\title{
Inhibitory learning of phototaxis by honeybees in a passive-avoidance task
}

\author{
Paul Marchal, ${ }^{1,5}$ Maria Eugenia Villar, ${ }^{1,4,5}$ Haiyang Geng, ${ }^{1,2}$ Patrick Arrufat, ${ }^{1}$ \\ Maud Combe, ${ }^{1}$ Haydée Viola, ${ }^{3}$ Isabelle Massou, ${ }^{1}$ and Martin Giurfa ${ }^{1,2}$ \\ ${ }^{1}$ Centre de Recherches sur la Cognition Animale (CRCA), Centre de Biologie Intégrative (CBI), Université de Toulouse, CNRS, UPS, \\ F-31062 Toulouse cedex 09, France; ${ }^{2}$ College of Bee Science, Fujian Agriculture and Forestry University, Fuzhou 350002, China; \\ ${ }^{3}$ Instituto de Biología Celular y Neurociencias (IBCN) "Dr Eduardo De Robertis," CONICET-Universidad de Buenos Aires, Buenos Aires \\ (C1121ABG), Argentina
}

\begin{abstract}
Honeybees are a standard model for the study of appetitive learning and memory. Yet, fewer attempts have been performed to characterize aversive learning and memory in this insect and uncover its molecular underpinnings. Here, we took advantage of the positive phototactic behavior of bees kept away from the hive in a dark environment and established a passive-avoidance task in which they had to suppress positive phototaxis. Bees placed in a two-compartment box learned to inhibit spontaneous attraction to a compartment illuminated with blue light by associating and entering into that chamber with shock delivery. Inhibitory learning resulted in an avoidance memory that could be retrieved $24 \mathrm{~h}$ after training and that was specific to the punished blue light. The memory was mainly operant but involved a Pavlovian component linking the blue light and the shock. Coupling conditioning with transcriptional analyses in key areas of the brain showed that inhibitory learning of phototaxis leads to an up-regulation of the dopaminergic receptor gene Amdopl in the calyces of the mushroom bodies, consistently with the role of dopamine signaling in different forms of aversive learning in insects. Our results thus introduce new perspectives for uncovering further cellular and molecular underpinnings of aversive learning and memory in bees. Overall, they represent an important step toward comparative learning studies between the appetitive and the aversive frameworks.
\end{abstract}

[Supplemental material is available for this article.]

Avoidance learning is a form of operant learning that allows animals to anticipate and elude noxious events in their environment (Krypotos 2015; LeDoux et al. 2017). Several protocols have been conceived to study the animals' capacity to learn that the emission or omission of a specific behavior results in the presence or the absence of an aversive stimulus (typically an electric shock). In rodents, for instance, active-avoidance and passive-avoidance learning protocols are commonly used to study avoidance learning. In active-avoidance learning, a specified response has to be produced by the animal to avoid the negative reinforcement (Wynne and Solomon 1955). For instance, a rat placed in a box with an electrified floor grid may learn that a discriminative stimulus (a light or a sound) anticipates shock delivery through the grid and that pressing a lever interrupts the punishment and the discriminative stimulus. The animal will thus exhibit shorter latencies and a higher frequency of lever pressing upon discriminative-stimulus onset. In passive-avoidance learning, on the contrary, a specified response needs to be suppressed to avoid the negative reinforcement (Venable and Kelly 1990; Kaminsky et al. 2001). For instance, rats, which spontaneously avoid bright illuminated areas to seek refuge in dark compartments learn that entering the dark compartment results in electric shock delivery. Learning results, therefore, in longer latencies to reenter the dark compartment as the animal inhibits its spontaneous response.

Despite their model status for research on invertebrate learning (Giurfa 2007; Menzel 2012), honeybees have been scarcely

\footnotetext{
4Present address: Institut de Génomique Fonctionnelle, CNRS, F-34094 Montpellier Cedex 05, France. ${ }^{5}$ These authors contributed equally to this work. Corresponding author: martin.giurfa@univ-tlse3.fr Article is online at http://www.learnmem.org/cgi/doi/10.1101//m.050120. 119.
}

studied using protocols of avoidance learning. Learning and memory in bees have been mostly studied using appetitive-learning protocols in which the animals learn to associate different types of sensory stimuli with sucrose reward, the equivalent of the nectar they search in flowers (Menzel 1985; Menzel and Müller 1996; Giurfa 2007). In a few studies, electric shock was used to establish either Pavlovian or operant aversive-learning protocols. For instance, in Pavlovian aversive learning, harnessed bees are trained to associate either olfactory, visual, or gustatory stimuli with an electric shock. In this case, the sting extension response is used as readout of learning and retention (Vergoz et al. 2007; Carcaud et al. 2009; Giurfa et al. 2009; Roussel et al. 2009, 2010, 2012; Mota et al. 2011; Guiraud et al. 2018). In addition, two operant variants of an active-avoidance learning protocol have been established in which freely walking bees confined into a tunnel learn to discriminate two sections displaying two different odors or colored lights, one paired with shock and the other not shocked (Agarwal et al. 2011; Kirkerud et al. 2013, 2017; Avalos et al. 2017). The bee has thus to avoid actively the color/odor paired with shock and move to the nonpunished stimulus. In this differential conditioning task, the amount of shock received by the bee depends, therefore, on the time spent in the reinforced compartment.

Passive-avoidance learning has been studied in harnessed bees, which learned to delay or withhold their proboscis when stimulated with an odorant paired with sucrose solution followed

\footnotetext{
C 2019 Marchal et al. This article is distributed exclusively by Cold Spring Harbor Laboratory Press for the first 12 months after the full-issue publication date (see http://learnmem.cshlp.org/site/misc/terms.xhtml). After 12 months, it is available under a Creative Commons License (AttributionNonCommercial 4.0 International), as described at http://creativecommons. org/licenses/by-nc/4.0/.
} 
by an electric shock (Smith et al. 1991). Yet, no protocol for the study of passive-avoidance learning has been established in the case of freely moving bees set under controlled laboratory conditions. Knowing that bees are positively phototactic when they leave a dark place and prepare to fly back to the hive (Menzel and Greggers 1985), we aimed at establishing a learning paradigm in which they would learn to inhibit this spontaneous behavior based on its pairing with an electric shock. We introduce here four main achievements: (1) the establishment of a novel passive-avoidance task in which bees learn to inhibit attraction to a blue light based on associating phototactic choice with electric shock; (2) the demonstration that this learning induces an avoidance memory that can be retrieved $24 \mathrm{~h}$ after training and that is specific to the learned light; (3) the characterization of the associations mediating this aversive learning; and (4) the finding that inhibitory phototaxis learning determines an up-regulation of the dopaminergic receptor gene Amdop1 in the mushroom bodies, consistently with the role of dopamine signaling in different forms of aversive learning in insects.

\section{Results}

\section{Honeybees learn to inhibit positive phototaxis in a passive-avoidance task}

Bees were individually placed within the conditioning setup termed ICARUS (Fig. 1 ), which was made of two compartments interconnected via a small passage (see Fig. 1 and Materials and Methods). Both compartments were illuminated with red light $(\lambda=640 \mathrm{~nm}$; Fig. 1E), which represents darkness for the bee confined in the setup (Fig. 1B). After a familiarization period, light in one of the compartments was switched to blue ( $\lambda=464 \mathrm{~nm}$; Fig. $1 \mathrm{E})$, thus triggering phototactic attraction (Fig. 1A,C). Paired bees, unpaired bees, and no-shock bees were used in this experiment (Fig. 2A, left). Paired bees that entered the blue compartment received the electric shock and the blue light was switched off $2 \mathrm{sec}$ afterward. Unpaired bees experienced noncontingent blue light and shock (the light was switched off $2 \mathrm{sec}$ after the bee entered the blue-lit compartment and the shock was delivered $28 \mathrm{sec}$ after shock offset, i.e., $30 \mathrm{sec}$ after the bee entered the illuminated compartment). No-shock bees received the light stimulations but no electric shock (Fig. 2A, left).

Figure $2 \mathrm{~B}$ shows that only the paired group increased progressively the latency to enter the blue-illuminated compartment during trials while no change in latency was found both for the unpaired and the no-shock group (ANOVA for repeated measurements; Groups: $F_{(2,46)}=24.07, P<0.001$; Trials: $F_{(3.145,144.7)}=$ $4.619, P<0.01)$. Moreover, we found a significant effect for the interaction of the two factors (Trials $\times$ Groups: $F_{(14,322)}=4.24, P<$ 0.001 ), confirming a difference in the dynamic of responses during trials between groups. A Dunnett's post-hoc test ratified the signifi- cant variation of latency between trials 1 and 8 for the paired group (mean diff $=-91.77, P<0.05$ ) and the absence of difference for the unpaired and the no-shock groups (unpaired: mean diff $=-1.273, P$ =0.99; no-shock: mean diff $=-4.17, P=0.07$ ). Thus, bees of the paired group learned to avoid the attractive blue light because they associated the action of entering into the blue-lit compartment with shock punishment (see Supplemental Fig. S1 and Supplemental Videos S1 and S2, which show the behavior of a paired bee towards blue light at the beginning and end of conditioning, respectively). Bees for which blue illumination and shock were not contingent (unpaired group) as well as bees that received no-shock (no-shock group) did not change their performance along with trials.

\section{Inhibitory learning of phototaxis induces a 24-h specific memory}

We then asked if this avoidance learning persists in time or if the fact of keeping them in darkness during $24 \mathrm{~h}$ away from the hive 
A
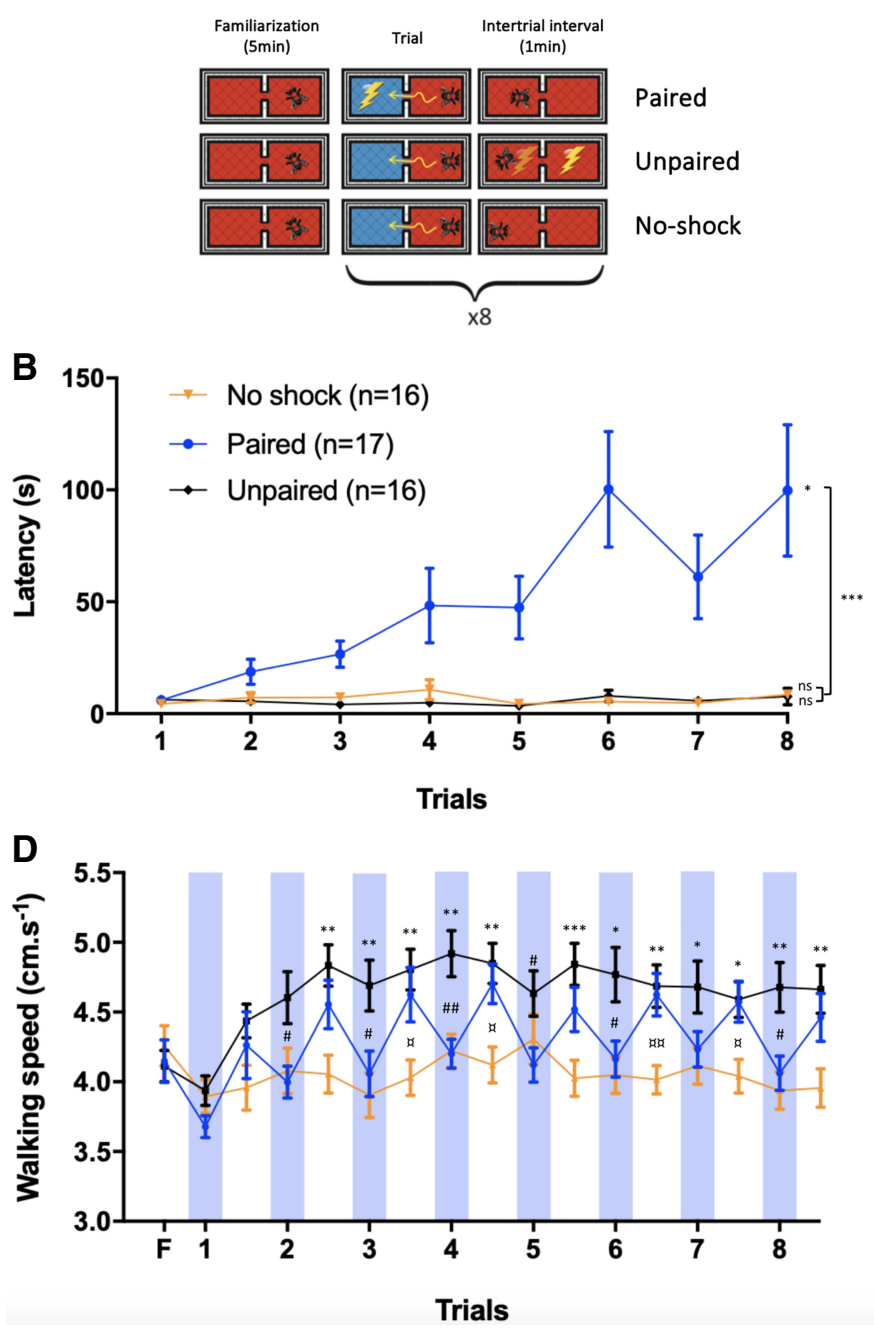

$\underline{\text { Test }}$
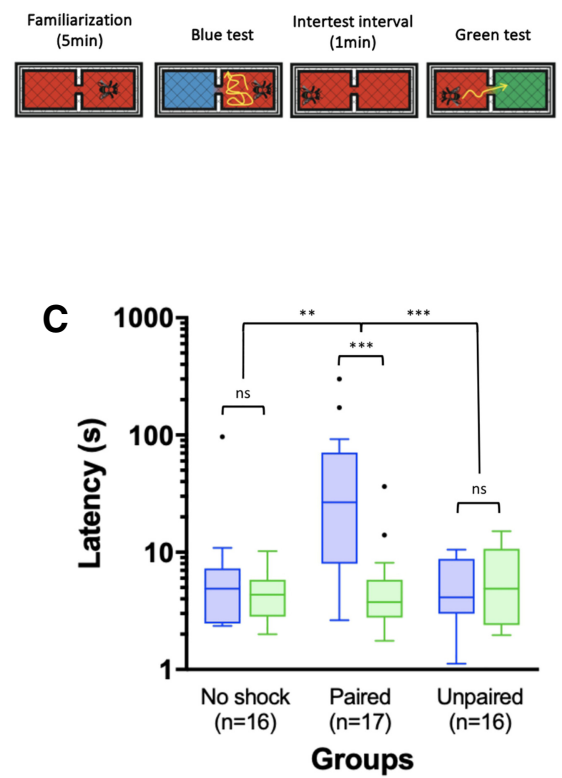

$\mathbf{E}$

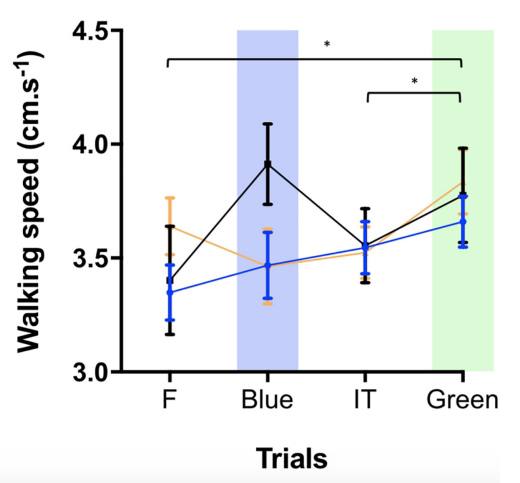

Figure 2. Multiple conditioning trials in a passive-avoidance task induce strong phototactic inhibitory learning and a memory retrievable $24 \mathrm{~h}$ after conditioning. $(A)$ Schematic representation of the experimental protocol. After a familiarization period of 5 min in the setup under red light, three groups of bees (paired, unpaired, and no-chock) were subjected to three conditioning protocols in which the latency to enter a blue-lit compartment was measured as a proxy of learning and memory. The paired group received eight conditioning trials in which the action of entering the blue-lit compartment was paired with a mild electric shock. The unpaired group received eight trials consisting of stimulations with attractive blue light and mild electric shock separated by $30 \mathrm{sec}$. The no-shock group received eight trials consisting in which only the stimulation with the attractive blue light was present. In all groups, trials were separated by an intertrial interval of $1 \mathrm{~min}$. Memory retention was tested $24 \mathrm{~h}$ after conditioning. The test session consisted of a familiarization period, and two tests separated by $1 \mathrm{~min}$. In the first test, one of the compartments was illuminated with blue light; in the second test, one compartment was illuminated with green light. No-shock was delivered during tests. (B) Learning curves represented in terms of the latency ( $s$ ) to enter the blue-lit compartment during conditioning trials for the three experimental groups. (C) Memory scores represented in terms of the latency (s) to enter the blue-lit and green-lit compartments. They are displayed in a logarithmic scale for better visualization. Each box extends from the 25th to 75th percentiles; the line in the middle of the box shows the median. Tukey's method was used for plotting whiskers and outliers. ( $D$ ) Mean walking speed (cm/ s) of bees of the three experimental groups during conditioning trials and intertrial intervals. Blue bars represent stimulations with blue light. \#: significant difference between paired and unpaired. *: significant difference between unpaired and no-shock. a: significant difference between paired and no-shock. $(E)$ Mean walking speed of bees $(\mathrm{cm} / \mathrm{sec})$ of each experimental group during the test session including familiarization, test trials, and intertest interval. Blue and green bars represent stimulation with blue and green lights, respectively. Error bars correspond to SEM. ns: nonsignificant, $\left({ }^{*}\right) P<0.05,\left({ }^{*}\right) P<0.01$, $\left({ }^{* * *}\right) P<0.001$.

results in either memory decay or in overriding of memory by enhanced phototaxis. To answer this question, we confined the bees from all three groups (paired, unpaired, and no-shock) individually in syringes and kept them in an incubator at $28^{\circ} \mathrm{C}, 70 \%$ humidity, in the dark during $24 \mathrm{~h}$. We then tested them in a memory retention session (Fig. 2A, right) to determine if bees kept the memory of their prior learning. Furthermore, bees were subsequently tested for their response to a green-illuminated compartment $(\lambda=523$ $\mathrm{nm}$, Fig. 1D,E) to determine if phototactic behavior (to green light) was kept intact. Both tests were spaced by 1 min.

Figure 2C shows that the latency to enter the blue-illuminated compartment remained higher than the latency to enter the green-illuminated compartment only in the paired group (Wilcoxon signed-rank test; paired: $W=147, P<0.001$; unpaired: $W=-38, P=0.30$; no-shock, $W=26, P=0.53)$, thus confirming the presence of a 24 -h memory in bees trained to suppress positive 
phototaxis toward blue light (Fig. 2B). Additionally, for each individual, we computed the difference between the latencies to enter the blue-lit and the green-lit compartment $\left(\Delta_{\text {latency }}=\right.$ latency blue $_{-}$ latency $\left.{ }_{\text {green }}\right)$. The $\Delta_{\text {latency }}$ of the paired group was significantly higher than that of the control groups (Kruskal-Wallis test; $K=$ 19.80, $P<0.001$; Dunn's multiple comparisons; paired vs. unpaired: mean rank diff $=21.18, P<0.001$; paired vs. no-shock: mean rank diff $=15.93, P<0.01$ ). This result thus confirms that bees of the paired group formed and retained a memory of their aversive experience while bees of the two control groups, which did not learn, had obviously no such a memory.

Video tracking of bees during conditioning allowed to compare their mean walking speed during the familiarization period, the conditioning trials and the intertrial intervals (Fig. 2D). A twoway ANOVA for repeated measurements showed that the walking speed varied significantly along familiarization, trials, and intertrial intervals, and also between groups (Trials: $F_{(8.305,382)}=7.92, P<$ 0.001; Groups: $\left.F_{(2,46)}=6.82, P<0.01\right)$ and that the pattern of variation was different between groups (Trials $\times$ Groups: $F_{(32,736)}=3.32$, $P<0.001)$. A Tukey's post-hoc test showed that bees of the three groups varied in walking speed at several trials and intertrial intervals (see Supplemental Table S1 for statistics). In the two groups that received a shock (paired and unpaired groups), the walking speed increased overall from the first conditioning trial to the second intertrial interval, and then remained constant. The no-shock group maintained the same basal speed as in the familiarization period all along with the trials. Thus, the repeated experience of the shock tended to increase the speed of the bees within the setup. This was particularly visible for the unpaired group, which could not establish predictions about the shock and exhibited the higher speed. Finally, the paired group exhibited a decrease in walking speed when confronted to the attractive light, which may reflect their attempt to avoid receiving the shock. In the test session (Fig. 2E), the walking speed varied significantly during familiarization, tests, and intertest intervals for all groups (two-way ANOVA for repeated measurements; Groups: $F_{(2,46)}=0.44, P=0.65$; Trials: $F_{(2.222,102.2)}=3.81, \quad P<0.05 ; \quad$ Trials $\times$ Groups: $F_{(6,138)}=1.96, \quad P=$ $0.076)$. More specifically, bees increased their walking speed between the familiarization period and the test with green light, and between the intertest interval and the test with green light (see Supplemental Table S1 for statistics).

Overall, these results validate a novel experimental procedure for the study of phototactic suppression using a passive-avoidance task. They show that bees learn to inhibit their strong innate tendency to go toward the light if kept in the darkness away from the hive and that this learning induces a memory that can be retrieved at least $24 \mathrm{~h}$ after conditioning. Bees behaved differently within the setup depending on having experienced or not an electric shock. Bees of the unpaired group, which could not predict the shock, moved faster while bees of the paired group, which learned the association between entering the blue-lit compartment and the shock, moved at intermediate speed. Bees of the no-shock group were slower.

\section{Inhibitory learning of phototaxis is mainly operant but involves a Pavlovian component}

In our protocol, the bee must inhibit phototactic responses to avoid receiving an electric shock. This scenario corresponds to a case of operant conditioning where the action of the animal is contingent to the reinforcement. Yet, learning could also rely on the contingency established between blue light and shock, which is of Pavlovian nature. Indeed, we previously demonstrated that the unpaired group (typical Pavlovian control) shows no sign of learning or memory. Yet, abolishing the temporal contingency between stimulus and reinforcement also abolishes the contingency between the action of the animal and the reinforcement. Thus, to determine if the inhibitory learning of phototaxis has the characteristics of an operant-conditioning task, we conditioned a master and a yoked group in parallel (Fig. 3A). The master group was identical to the paired group of the previous experiment. The yoked group received the same amount of electric shock as the paired group but as shock was decided by the action of the master bee, it was not necessarily contingent with the action of entering the lit compartment (Fig. 3A, left). If learning were purely operant, an increase of latency should be observed in the master but not in the yoked group. After conditioning, both the master and the yoked groups were tested for 24-h memory retention by presenting sequentially the conditioned blue light and the unconditioned green light (Fig. 3A, right).

During conditioning, a significant difference in the latency to enter the blue-illuminated compartment was found between the master and the yoked group (Fig. 3B; two-way ANOVA for repeated measurements; Groups: $\left.F_{(1,32)}=10.14, P<0.01\right)$. Responses varied during trials $\left(F_{(4.012,128.4)}=5.48, P<0.001\right)$ and a marginally nonsignificant interaction between factors was found (Trials $\times$ Groups: $\left.F_{(7,224)}=1.88, P=0.07\right)$, thus showing that latencies increased mainly in the master group and that the pattern of variation tended to be similar in yoked and master bees. Indeed, both groups showed an increase in the latency to enter the blueilluminated compartment during trials (latency below $10 \mathrm{sec}$ both for master and yoked bees in the first trial, and around 100 and $25 \mathrm{sec}$ in the eighth trial for master and yoked bees, respectively (master: mean diff $=-81.91, P<0.05$; yoked: mean diff $=-20.14$, $P<0.05)$.

In the memory test (Fig. 3C), the yoked group showed a tendency to have a higher latency to enter the blue-lit compartment (Wilcoxon signed-rank test, $W=73, P=0.09$ ), which may confirm the results obtained at the end of the conditioning. Yet, this tendency has to be considered with caution in the light of the procedure used to quantify the latency of this group (see Materials and Methods). In any case, the master group presented a latency to enter the blue-lit compartment that was significantly higher than that for the green-lit one (Wilcoxon signed-rank test, $W=153, P<0.001$ ), consistently with the presence of a 24-h memory. Accordingly, a comparison between the $\Delta_{\text {latencies }}$ of both groups showed a significant difference in favor of the master group (Mann-Whitney test: $U=82, P<0.05)$.

The walking speed of master and yoked bees varied significantly during familiarization, trials, and intertrial intervals but not between groups (Fig. 3D; two-way ANOVA for repeated measurements; Trials: $F_{(7.262,232,4)}=20.53, \quad P<0.001$; Groups: $\left.F_{(1,32)}=0.99, P=0.33\right)$. Yet, the interaction between Trials and Groups was significant (Trials $\times$ Groups: $F_{(16,512)}=3.29, P<0.001$ ), thus showing that the pattern of responses varied differently between master and yoked bees. In both groups, the walking speed increased after the first conditioning trial and then remained constant during the rest of the conditioning (see Supplemental Table S2 for statistics). It was high during intertrial intervals and low in the presence of blue light during trials. This similarity in performance is consistent with the occurrence of learning in both groups. This result confirms that bees increased their basal speed in response to the first shock acting as an arousing stimulus and that they decreased their walking speed when confronted to the attractive light acting as an inhibitory stimulus. Note that despite the absence of significant difference between groups, the master group tended to have a lower speed than that of the yoked group, in particular during certain intertrial intervals (Fig. 3D). In the test session (Fig. 3E), the walking speed varied significantly during familiarization, tests, and intertest interval for all groups (two-way ANOVA for repeated measurements; Trials: $\left.F_{(2.74,87.69)}=5.29, P<0.01\right)$. Neither the group effect (Groups: $F_{(1,32)}=1.22, P=0.28$ ) nor the interaction 
A

\section{Conditioning}
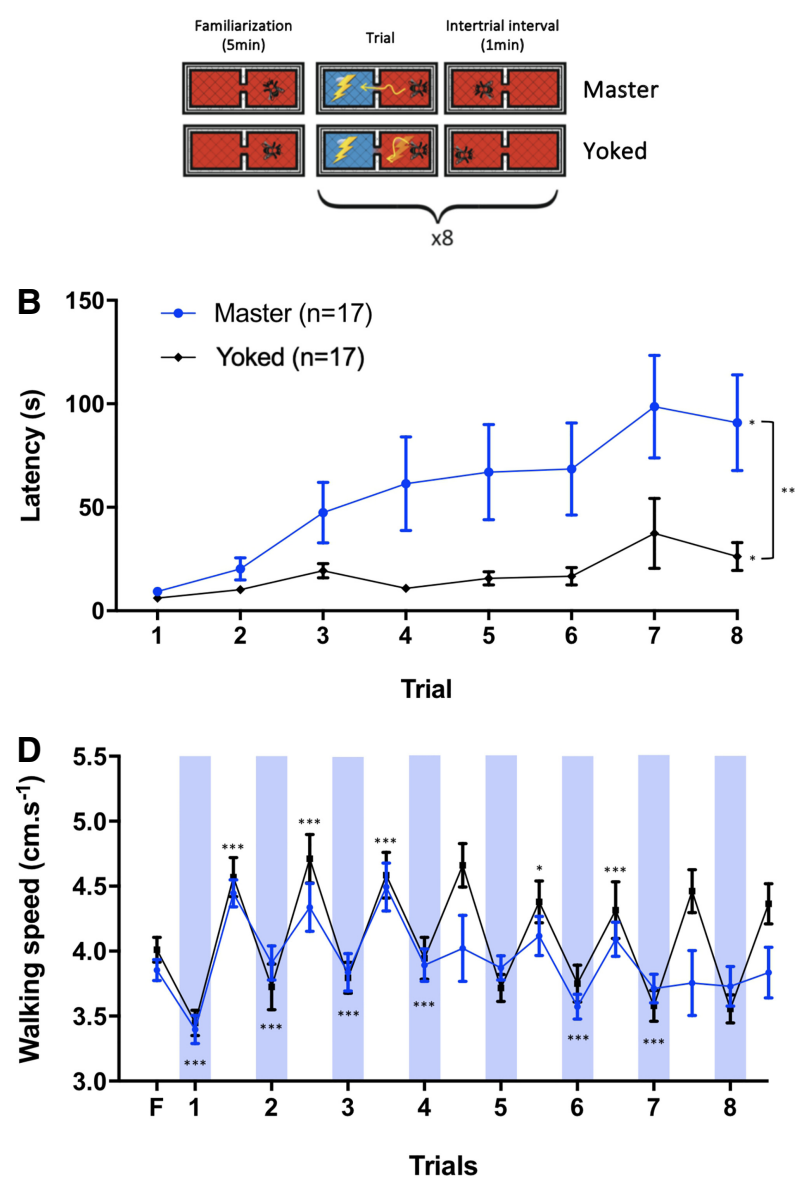

$\underline{\text { Test }}$
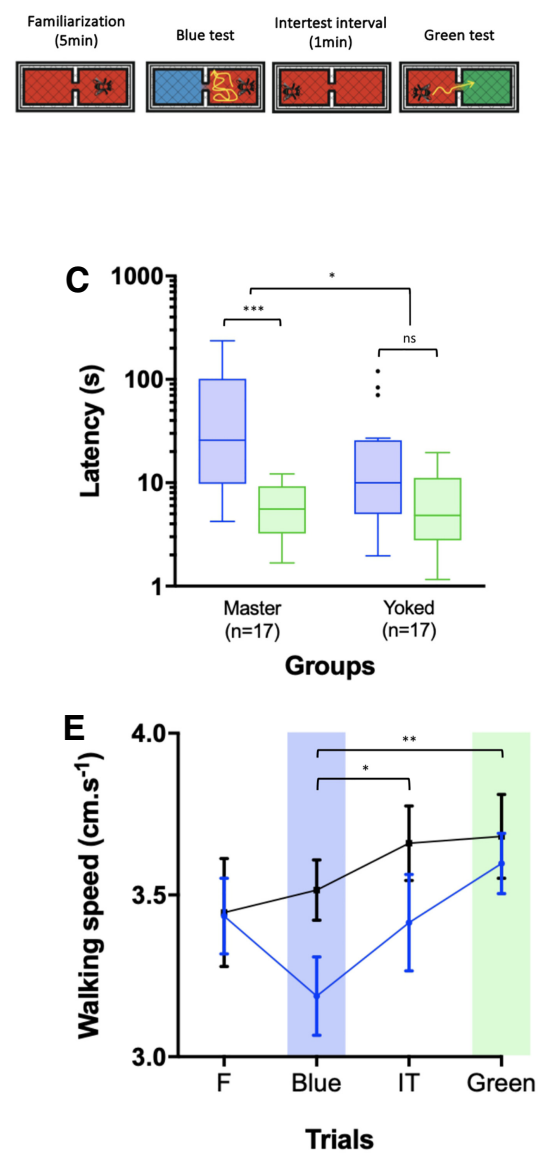

Figure 3. Inhibitory learning of phototaxis is mainly operant but involves a Pavlovian component. (A) Schematic representation of the experimental protocol. After a familiarization period of $5 \mathrm{~min}$ under red light in the setup, two groups of bees (master and yoked) were subjected to two conditioning protocols in which the latency to enter a blue-lit compartment was measured as a proxy of learning and memory. The master group received eight conditioning trials during which the action of entering the blue-lit compartment was paired with a mild electric shock. Each bee in the yoked group received eight trials consisting of stimulations with the attractive blue light and the mild electric shock following the exact same temporal sequence as that of its corresponding master bee. In both groups, trials were separated by intervals of $1 \mathrm{~min}$. Memory retention was tested $24 \mathrm{~h}$ after conditioning. The test session consisted of a familiarization period, and two tests separated by $1 \mathrm{~min}$. In the first test, one of the compartments was illuminated with blue light; in the second test, one compartment was illuminated with green light. No-shock was delivered during tests. (B) Learning curves are represented in terms of the latency (s) to enter the blue-lit compartment during conditioning trials for the two experimental groups. (C) Memory scores are represented in terms of the latency (s) to enter the blue-lit and green-lit compartments. They are displayed in a logarithmic scale for better visualization. Each box extends from the 25th to 75 th percentiles; the line in the middle of the box shows the median. Tukey's method was used for plotting whiskers and outliers. (D) Mean walking speed $(\mathrm{cm} / \mathrm{s})$ of bees of each experimental group along with conditioning trials and intertrial intervals. Blue bars represent stimulations with blue light. $(E)$ Mean walking speed of bees $(\mathrm{cm} / \mathrm{s})$ of each experimental group during the test session including familiarization, test trials, and intertest interval. Blue and green bars represent stimulation with blue and green lights, respectively. Error bars correspond to SEM. ns: nonsignificant, $\left({ }^{*}\right) P<0.05,\left({ }^{\star *}\right) P<0.01,\left({ }^{* \star \star}\right) P$ $<0.001$.

(Trials $\times$ Groups: $\left.F_{(3,96)}=1.8, P=0.15\right)$ was significant. Both groups increased their walking speed after the test to the blue light (see Supplemental Table S2 for statistics).

Taken together, these results confirm the main operant nature of the inhibitory learning of phototaxis by honeybees and a contribution of a Pavlovian association between blue light and electric shock.

\section{Inhibitory learning of phototaxis up-regulates Amdop1 receptor in the calyces of the mushroom bodies}

In a third experiment, we aimed at determining if inhibitory learning of phototaxis induces transcriptional changes immediately postlearning, which might participate either in memory consolidation or in amplifying the representation of reinforcement and/ or the light used as discriminative stimulus. To this end, we performed RT-qPCR in individual brains of animals trained as in the previous experiments and focused on expression levels of the three dopamine-receptor genes Amdop1, Amdop2, and Amdop3 (Beggs et al. 2011), the main octopamine receptor gene Amoct $\alpha$ R1 (Farooqui et al. 2004; Sinakevitch et al. 2011) and the serotonin receptor gene Am5-ht1a (Thamm et al. 2010). These genes were selected based on the involvement of their associated signaling pathways in different forms of appetitive and aversive learning, as well as in visually mediated responses (see Materials and Methods). 
Figure $4 \mathrm{~A}$ shows the learning performance of bees of the paired and the unpaired groups. Bees of both groups differed in their latency to enter into the blue-lit compartment during trials. Indeed, we found a significant interaction between factors (two-way ANOVA for repeated measurements; Trials $\times$ Groups, $F_{(7,196)}=6.74, \quad P<0.001 ; \quad$ Trials, $\quad F_{(5.019,140.5)}=6.212, \quad P<0.001$; Groups, $\left.F_{(1,28)}=47.5, P<0.001\right)$, which shows that both groups responded differently along conditioning trials. Only the paired group increased the latency to enter the blue-illuminated compartment (from below 10 to $150 \mathrm{sec}$ from the first to the eighth trial; Dunnett's multiple comparisons tests; mean diff $=-161.9, P<$ $0.001)$. On the contrary, no significant increase was found for the unpaired group (mean diff $=-0.664, P=0.182$ ).
Bees were anesthetized on ice for 5 min immediately after conditioning; the head was then removed and frozen in liquid nitrogen to be stored at $-80^{\circ} \mathrm{C}$ until dissection. Individual brains were dissected and separated in sections enriched in $\mathrm{OL}, \mathrm{MBc}, \mathrm{AL}$, and CB (Fig. 4B). The RNA of each section was extracted, retrotranscripted and amplified (RT-qPCR). Levels of expression in each brain section in each individual were relativized and normalized to three reference genes ( $R p s 8, R p 49$, and $E f 1 \alpha$ ).

In the calyces of the mushroom bodies (Fig. 4C), we found a significant increase in the expression of the Amdop1 receptor gene in the paired group with respect to the unpaired group (unpaired $t$-test; $t=2.09, \mathrm{df}=27, P<0.05)$. No other difference was found with respect to the other receptor genes analyzed. In the
A

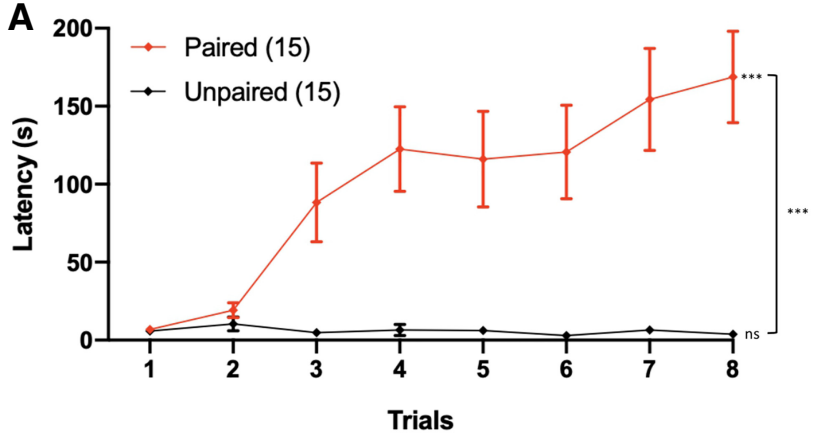

C

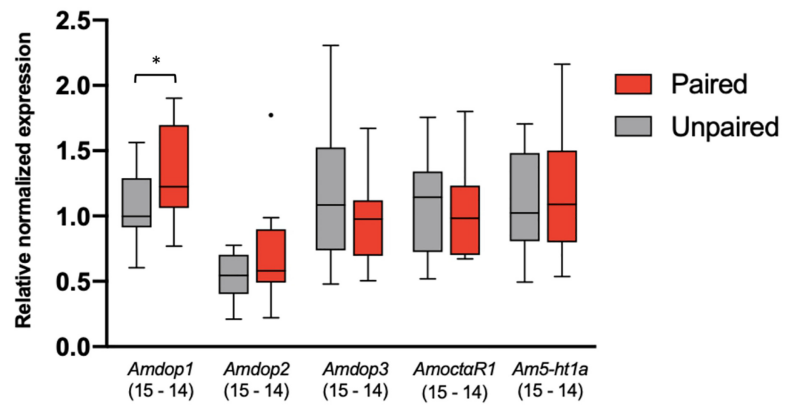

$E$

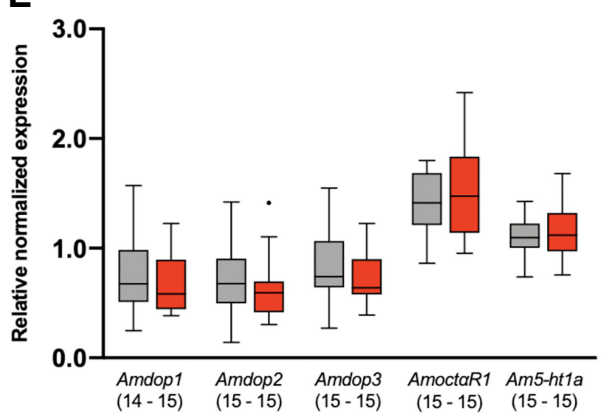

B

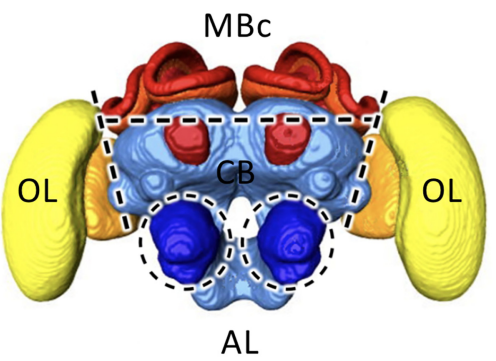

D

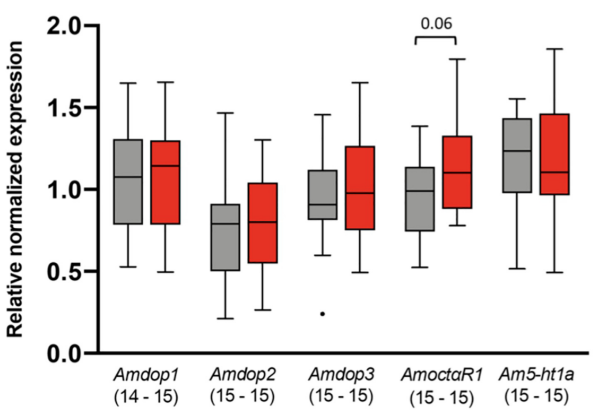

$\mathbf{F}$

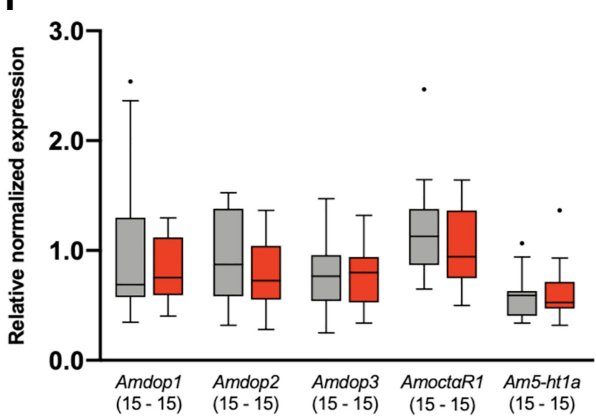

Figure 4. Inhibitory learning of phototaxis up-regulates Amdop1 receptor genes in the calyces of the mushroom bodies. ( $A$ ) Learning curves represented in terms of the latency $(s)$ to enter the blue-lit compartment during conditioning trials for the two experimental groups, paired and unpaired. Error bars correspond to SEM. (B) Schematic representation of brain dissections. Brains were separated in four sections enriched in mushroom bodies calyces (MBc, red), optical lobes (OL, yellow), antennal lobes (AL, dark blue) and central brain ( $C B$, light blue), respectively. ( $C-F)$ Relative normalized expression of five genes of interest (Amdop1, Amdop2, Amdop3, AmoctaR1, and Am5-ht1 a receptors) in each of the four dissected brain regions of paired and unpaired conditioned bees. The expression of each gene of interest was normalized to the expression of three genes of reference (Ef1a, Rps8, Rp49) for each bee. Expression distribution is represented as boxplots. Each box extends from the 25th to 75th percentiles; the line in the middle of the box shows the median. Tukey method was used for plotting whiskers and outliers. ns: nonsignificant, $\left({ }^{*}\right) P<0.05,\left({ }^{* * *}\right) P<0.001$. 
CB (Fig. 4D), no significant difference was found; yet a marginally nonsignificant tendency was found $(P=0.06)$ in the case of the Amoct $\alpha$ R1 gene, which was slightly increased in paired bees. In the cases of the OL (Fig. 4E) and the AL (Fig. 4F), no changes in receptor gene expression were detected between paired and unpaired bees.

\section{Discussion}

We used a novel passive-avoidance task to study the consequences of associating phototactic attraction toward a blue light with the negative reinforcement of an electric shock in honeybees. We found that bees learn to suppress this attraction and form a memory of this association that could be retrieved at least $24 \mathrm{~h}$ after the end of the training. Learning was mostly operant as the decision and behavior of the trained bees controlled shock delivery but included a nonnegligible Pavlovian component based on associating the blue light to the shock. Video recording and analysis of the bees' behavior during conditioning and retention tests revealed that the electric shock elicited higher walking speed, consistently with an arousing effect and with an intent to flee the aversive context. However, bees also reduced drastically their walking speed when facing the blue light. This fact may reflect a conflict situation between being attracted to the blue light-driven by phototaxis and the negative outcome experienced upon entering the blue-lit compartment. Finally, using RT-qPCR, we demonstrate that inhibitory learning of phototaxis correlates with a specific increase of the Amdop1 receptor gene in the calyces of the mushroom bodies immediately after conditioning.

Phototaxis suppression was still observable $24 \mathrm{~h}$ after training, thus showing the strength of learning achieved in this passiveavoidance task. Indeed, given that phototaxis represents a strong innate behavior in bees (Menzel and Greggers 1985), which is accentuated by keeping the bees in darkness away from the hive during more than $24 \mathrm{~h}$, one could have predicted that learning would be either overridden or outcompeted by phototaxis $1 \mathrm{~d}$ after conditioning. Yet, the fact that memory was still visible underlines the remarkable plasticity of bee behavior in which acquired information can overcome innate tendencies (Roussel et al. 2012). In the Drosophila's heat box, a fly walking freely back and forth in a narrow alley in complete darkness is conditioned to avoid one half of the length of the alley by being heated instantaneously upon entering it (Wustmann et al. 1996; Wustmann and Heisenberg 1997). Conditioning is an operant process as flies learn to avoid the punished half of the chamber and spend more time on the "unpunished" half. In this setup, memory retention was measured right after training and it was shown to depend on a win-stay component (staying on the unpunished side after avoiding the last heat encounter) rather than on associative memory (Putz and Heisenberg 2002). This strategy is excluded in our case, as bees were tested $24 \mathrm{~h}$ after training and after being kept in a different context (an individual syringe placed in an incubator) until the memory test. This procedure also excludes the use of scent marks released during the shock given the time elapsed since training and the fact that tests were always done in the absence of shock. When a change of context was applied to flies trained in the heat box, retention tests revealed the presence of an aversive position memory that lasted only $2 \mathrm{~h}$ after the training (Putz and Heisenberg 2002). Although positional cues and heat may be less salient than the light and the electric shock used in our experiments, the 24-h memories present in bees underline again their remarkable behavioral plasticity.

The study of the associations established in our protocol confirmed the operant nature of the inhibitory learning of phototaxis by honeybees. Bees of the master group showed significant learn- ing and retention performances, which were better than those of the yoked group (Fig. 3). Yet, the yoked group showed some evidence of learning, which could rely on the acquisition of a Pavlovian association between the blue light and the shock, independently of their motor actions. The residual learning of the yoked group could also be due to the fact that at the beginning of training the blue light was equally attractive to both master and yoked bees, thus resulting in coincident punishment delivery. This would induce learning in both groups, which would be further accentuated by successive trials in the master group. In the yoked group, the contingency between entering the blue-lit compartment and the shock would be progressively decreased.

The study of operant aversive learning has led to the establishment of two similar setups in the honeybee, which rely on activeavoidance (Kirkerud et al. 2013, 2017; Avalos et al. 2017; Dinges et al. 2017). In both cases, bees learn that one of two odors, or two colors, is paired with a shock so that they learn to choose the nonpunished stimulus and avoid the punished one. The response is expressed in terms of a preference index that takes into account the choice of the punished (CS+) versus the nonpunished stimuli (CS-). It is measured not only during the presentation of the CS+ but also during delivery of the shock that is associated to it, thus rendering response and acquisition evaluation difficult (Kirkerud et al. 2013, 2017; Avalos et al. 2017; Dinges et al. 2017). On the contrary, our behavioral readout, the latency to enter the blue-lit chamber, is an exclusive response to the blue light and does not involve the presence of shock during its quantification. So far, memory has not been assessed in the active-avoidance setups in which honeybee learning has been studied. It would be interesting to determine the memories arising in these protocols and compare them with those emerging in our passive-avoidance protocol.

Passive-avoidance tasks have been repeatedly used in rats to study learning and memory (Netto and Izquierdo 1985; Gold 1986; Izquierdo et al. 2000). In a step-through task, rats, which are innately photophobic, prefer to stay in a lit compartment when facing a choice between staying in a well-illuminated compartment and entering into a dark one. This avoidance is the result of having reinforced negatively the dark compartment with an electrical shock (McGaugh 1966; Roozendaal and McGaugh 2011). In a step-down task, a rat placed in an elevated platform steps down onto a metallic grid to explore it and receives thereby an electric shock. When the animal is placed back in the platform, it suppresses its stepping down (Jarvik and Kopp 1967; Viola et al. 2000; Tomaiuolo et al. 2015). Memories that last from $30 \mathrm{~min}$ to more than $30 \mathrm{~d}$ can be induced in both tasks by modifying the amount or the strength of electric shock experienced during the training (Izquierdo et al. 2006; Moncada and Viola 2007; Gonzalez et al. 2014; Tomaiuolo et al. 2015). Although we did not vary punishment intensity in our protocol, the possibility of inducing different memories through this variation is an interesting question for future experiments.

As biogenic-amine receptor genes mediate either appetitive or aversive reinforcement signaling (Giurfa 2006; Waddell 2010, 2013; Perry and Barron 2013; Das et al. 2016), we hypothesized that learning could be associated with rapid changes in the expression of these genes. Changes in gene expression related to memory formation, in particular in the case of long-term memories, may appear long after the period of 10-30 min postconditioning chosen in our work. Yet, here we did not put the accent on memory formation but on how learning may modify signaling pathways processing the sensory stimuli involved in our conditioning protocol (i.e., shock, light). We hypothesized that conditioning may enhance aminergic pathways underlying the processing of these stimuli as a way to enhance their salience. We thus chose to perform the quantification of RNA expression shortly after the end 
of conditioning, in the same way as differences in immediate early genes expression are indicative of enhanced neural activity for a sensory stimulus. We found that inhibitory learning of phototaxis was associated with an up-regulation of the Amdop1 receptor gene in the calyces of the mushroom bodies. This variation is coherent with previous findings that demonstrated the implication of dopamine in aversive learning in bees and other insects where it mediates the reinforcing properties of punishment-like stimuli (Unoki et al. 2005; Vergoz et al. 2007; Claridge-Chang et al. 2009; Mizunami et al. 2009; Aso et al. 2012; Dacks et al. 2012). It also underlines the implication of mushroom-body calyces in learning and memory (Heisenberg 2003; Giurfa and Sandoz 2012; Menzel 2014). The dopaminergic receptor genes Amdop1, Amdop2, and Amdop3 code for three dopamine receptors termed AmDOP1, AmDOP2, and AmDOP3, respectively. While AmDOP1 and AmDOP2 are considered D1-like receptors because dopamine binding results in increased cAMP levels in cells expressing them, AmDOP3 is considered a D2-like receptor because dopamine binding results in a reduction of cAMP levels (Beggs et al. 2011). Differences exist between the two D-1 like dopaminergic receptors because AmDOP1 requires lower concentrations of dopamine for activation compared with AmDOP2 (Mustard et al. 2003). Differences are also found at the receptor-gene level. A study on age-related changes in the expression of dopaminergic receptor genes showed that Amdop1 does not change its expression levels across the age groups tested. On the contrary, levels of expression of $A m d o p 2$ were very variable, particularly during the first week of adult life (McQuillan et al. 2012). These characteristics render Amdop1 particularly suitable to mediate the reinforcing properties of the electric shock in a stable, age-independent manner. Interestingly, we found a barely nonsignificant up-regulation of the octopaminergic receptor gene AmoctaR1 in the CB section. Octopamine is involved in appetitive learning as it mediates sucrose-reward signaling (Hammer and Menzel 1998); yet, its role in vision should not be forgotten. Indeed, OA modulates motionsensitive neurons in the lobula, one of the visual neuropils integrating the optic lobes of the bee brain (Erber and Kloppenburg 1995; Kloppenburg and Erber 1995). Moreover, high levels of OA are found in the optic lobes of pollen foragers, which exhibit reduced phototaxis (Scheiner et al. 2014). A similar relationship was not found for the mushroom bodies, and neither expression of AmoctaR1 did vary between optic lobes and mushroom bodies in relation to phototaxis (Scheiner et al. 2014). However, our findings refer to an area of the brain (CB) that included neuropils not considered in the study of phototaxis in pollen foragers (Scheiner et al. 2014). It is thus possible that the tendency toward an up-regulation of Amoct $\alpha R 1$ reflects learning-dependent phototaxis suppression and that it takes place in central areas of the brain such as the central complex (Pfeiffer and Homberg 2014).

Further studies should explore this possibility as well as determine the molecular underpinnings of the memories arising from our training. Exploration of this novel form of inhibitory learning opens the door for new comparative studies of operant learning in bees and flies and provides, therefore, new research avenues for the study of insect learning and memory.

\section{Materials and Methods}

\section{Insects}

Honeybees were obtained from outdoor hives of our apiary located in the campus of Paul Sabatier University. The bees used for the experiments were foragers collected at feeders filled with $40 \%(\mathrm{w} / \mathrm{w})$ sucrose solution to which they were previously trained. Bees were collected each day and placed in a small plastic box where a $50 \%$ (w/w) sugar solution was made available. Each bee could obtain an average of $5 \mu \mathrm{L}$ of that solution. The box was placed in an incu- bator at $28^{\circ} \mathrm{C}$ and $70 \%$ humidity during at least 30 min before the experiments began. If the time before experiments was longer, bees were fed every $3 \mathrm{~h}$ with $5 \mu \mathrm{L}$ of $50 \%$ sugar solution to ensure high vitality.

\section{Setup}

The conditioning apparatus, termed ICARUS, consisted in a plastic rectangular box $(14 \mathrm{~cm} \times 7 \mathrm{~cm} \times 0.8 \mathrm{~cm}$, on the inside) made of two chambers connected by a small passage $(1 \mathrm{~cm}$ width) (Fig. 1$)$. The floor and ceiling were two metallic grids connected to a hightension generator that allowed delivering an electric shock (1.3 $\mathrm{kV}, 65 \mu \mathrm{A}, 200 \mathrm{msec}$ ) to the bee. The space between them was reduced so that the bee could only walk but not fly within the setup. Each chamber was surrounded by a set of 19 RGB LEDs ( $\lambda^{\text {blue }}=$ $464 \mathrm{~nm}, \lambda^{\text {green }}=523 \mathrm{~nm}$, and $\lambda^{\text {red }}=640 \mathrm{~nm}$; Fig. 1 ) controlled by an Arduino Mega (Supplemental Fig. S2). In this way, both chambers could be lit in the same color, or in different colors. Red color was chosen to provide the equivalent of a dark surrounding to the bees given the absence of chromatic sensitivity in this range of the spectrum (Reisenman and Giurfa 2008). Experiments were recorded from the top by a HD video camera (Legria HF R806, Canon) (Fig. 1). Videos obtained can be used to observe and quantify behaviors (Supplemental Videos S1, S2). A video tracking software developed at the CRCA and under the CECILL free license of the CNRS allowed automated quantification of the bee position during the time ( $25 \mathrm{fps})$. As the only moving object in the scene was the bee, the software determines its position using the difference between successive images. Filters were applied to remove the noise related to the brightness changes. Thresholding of the three RGB channels of the image allowed detecting and identifying the chromatic stimuli. At the end of the analysis, postprocessing was performed to calculate the latencies to cross toward the light and the average walking speed of bees during familiarization, trials, and intertrial intervals. Post-processing also enables for retracing the trajectories of the bees during successive trials (Supplemental Fig. S1).

\section{Conditioning protocol}

All the experiments were conducted under red light (see above). The red LEDs of the setup were always on to facilitate tracking of the bee. In all experiments, the "paired" group experienced an electric shock upon entering the compartment that was lit in blue. Three different controls ("unpaired," "no-shock," and "yoked") were used in different experiments (see below, and Figs. 2A, 3A, left) and run in parallel with the paired group.

\section{Training session, paired conditioning}

During a phase of familiarization, the bee was allowed to explore freely the two chambers of the setup (under dark conditions, red-illuminated) for $5 \mathrm{~min}$ before the beginning of the first conditioning trial. A conditioning trial began when the compartment opposite to the one occupied by the bee was illuminated with a blue light. This only happened when the bee was located facing the wall opposite to the passage connecting the two compartments. This procedure allowed standardizing the position and distance to cross between bees. When the blue light was turned on, the bee driven by its innate positive phototaxis entered into the blue-illuminated compartment and received the electric shock during $200 \mathrm{msec}$. Two seconds after shock offset, the light was switched to red (only red light illumination remains). If $5 \mathrm{~min}$ after blue-light onset the bee did not enter the blue-illuminated chamber, the light was turned off and the trial finished without electric shock. This means that every trial had a possible maximal latency of $5 \mathrm{~min}$. From all the bees subjected to paired conditioning (Figs. $2-4), 34.69 \%$ were in this situation in at least one of the conditioning trials. The intertrial interval was 1 min during which only red illumination was present. Overall, training consisted of familiarization and eight trials spaced by seven intertrial intervals. In all cases, we quantified the latency to enter into the blue-lit compartment, which is a proxy of learning and memory. Other parameters such 
as the walking speed of each trained bee could be extracted from the videos. At the end of the training session, each bee was placed inside a $5 \mathrm{~mL}$ pierced plastic syringe and immediately fed with $5 \mu \mathrm{L}$ of $50 \%(\mathrm{w} / \mathrm{w})$ sugar solution. The solution was renewed every $3 \mathrm{~h}$ until the last feeding of the day, which took place at around 6 p.m. and which consisted of $20 \mu \mathrm{L}$ of $50 \%$ sugar solution to overcome the night. The syringes containing the bees were placed in an incubator at $28^{\circ} \mathrm{C}$ and $70 \%$ until the $24 \mathrm{~h}$ test session. In the morning of the test-session day, bees were fed with $10 \mu \mathrm{L}$ of $50 \%$ sugar solution, and if the test session occurred more than $3 \mathrm{~h}$ later, 5 $\mu \mathrm{L}$ of $50 \%$ sugar solution was further supplied.

\section{Test session}

Two memory-retention tests were performed $24 \mathrm{~h}$ after the end of conditioning (Figs. 2A, 3A, right). The test session included a familiarization period of $5 \mathrm{~min}$ inside the setup under red-light conditions, which was followed by the first test. This test was identical to a conditioning trial with the difference that no-shock was delivered upon entering the blue-lit compartment. Once the test 1 finished, and after an intertest interval of $1 \mathrm{~min}$ under red-light conditions, the second test was performed in which green light was used. The main goal of the test with the green light was to demonstrate that the innate phototactic tendency was still present and that the potential increase in the latency to enter the blue-lit compartment in the first test was only due to the previous aversive experience, instead of being due to motor fatigue or loss of light sensitivity, among others. Therefore, the test with green light was performed always after the test with blue light.

\section{Experimental controls}

The following control groups were used in different experiments: no-shock group: bees were trained in a way similar to the paired group but in the absence of electric shock. This group was used to determine if the increase in latency along trials of the paired group was due to sensory or motor fatigue or to a progressive loss of phototactic motivation; unpaired group: bees were trained with noncontingent blue light and electric shock; for these bees, a trial started when the opposite chamber was illuminated; the bee attracted by the light entered the lit compartment and 2 sec after this, the light was turned off. The electric shock was delivered 28 sec after the light was turned off, that is, under red-light conditions and 30 sec after the bee entered the lit compartment. In this way, we controlled for a possible Pavlovian association between light and shock; yoked group: bees of the yoked group received the electric shock independently of their behavior but dependently on the behavior exhibited by bees in a master group (paired group; see above). The yoked group is commonly used as a control in operant protocols as it allows determining if changes in latency in the master group are due to operant learning, that is, to the association between the action of entering the blue-lit compartment and the consequences of this action, receiving an electric shock. In shuttle boxes, in which subjects have to commute between a punished and a nonpunished compartment, yoked subjects should experience the blue light and the shock when the master group experienced them, taking into account the appropriate compartment for this experience. As for the master bees the light was switched on in the compartment opposite to their actual location to trigger phototaxis, a potential problem arises for yoked bees. Indeed, reproducing a master bee's situation may imply delivering the blue light either in the opposite chamber to the one where the yoked bee was located or to be forced to deliver it in the chamber where it was located. In the latter case, no latency to go to the light can be measured. Hence, no acquisition curve can be obtained. To avoid this problem, yoked bees in this situation were offered the blue light in the compartment opposite to their actual location. The onset of the electric shock was determined by the master bee's behavior. If the yoked bee exhibited a higher latency than its corresponding master bee, it received the shock without entering the lit compartment. In these cases, the latency assigned to the yoked bee was that of its corresponding master bee. Although this strategy may underestimate learning in the yoked group, it of- fers a conservative way to quantify latencies in both masters and yoked bees and overcomes the problem of yoked subjects commuting between two compartments in a shuttle box.

\section{Molecular analyses}

We quantified variations in receptor-gene expression resulting from inhibitory learning of phototaxis. We focused on biogenicamine receptor genes given the fundamental role of biogenic amines for different forms of insect learning, where they mediate either appetitive or aversive reinforcement signaling (Giurfa 2006; Waddell 2010, 2013; Perry and Barron 2013; Das et al. 2016). We focused on the three dopamine-receptor genes identified for the honeybee Amdop1, Amdop2, and Amdop3 (Beggs et al. 2011), given the essential role of dopamine for aversive reinforcement signaling in this insect (Vergoz et al. 2007; Tedjakumala and Giurfa 2013; Tedjakumala et al. 2014). We also quantified expression of the main octopamine receptor gene AmoctaR1 (Farooqui et al. 2003, 2004; Beggs et al. 2011; Sinakevitch et al. 2011) due to the inverse relationship found between octopamine levels in the optic lobes of bee foragers and their phototactic responses (Scheiner et al. 2014). Finally, we also measured levels of the serotonin receptor gene Am5-ht1a, which has been shown to be highly expressed in brain regions involved in visual information processing and which has a strong impact on phototactic behavior (Thamm et al. 2010). As reference genes, we used the Rps8 (ribosomal protein S8), the Rp49 (ribosomal protein 49), and the Ef1 $\alpha$ (translation elongation factor 1) genes, which are suitable genes for normalization in RT-qPCR analyses in the honeybee (Lourenço et al. 2008). Moreover, preliminary experiments allowed verifying that the two experimental groups did not differ with respect to these genes.

Paired and unpaired bees were put on ice for 5 min immediately after conditioning. They were then decapitated and the head was pasted to a slide with O.C.T compound (Mounting medium for cryotomy, VWR chemicals) and frozen in liquid nitrogen. All the brains were stored at $-80^{\circ} \mathrm{C}$ until dissection.

\section{Dissection}

The frozen bee head was dissected on dry ice under a binocular magnifier. First, the antennae were removed and a window was cut in the upper part of the head capsule, removing the cuticle between the compound eyes and the ocelli. Second, the glands and tracheae around the brain were removed. Third, the retinas of the compound eyes were also removed. Finally, the brain was cut in four sections separating the $\mathrm{AL}$, the $\mathrm{OL}$, the upper part of the mushroom bodies (the mushroom-body calyces, $\mathrm{MBc}$ ), and the remaining CB, which included mainly the central body, the subesophageal zone and the peduncula of the mushroom bodies (Fig. 4B). Samples were stored at $-80^{\circ} \mathrm{C}$ before RNA extraction.

\section{RNA extraction}

The RNA from the four sections mentioned above (AL, OL, MBc, and $\mathrm{CB}$ ) was extracted and purified using a Quick-RNA Miniprep Kit (Zimo Research). The final RNA concentration obtained was measured by spectrophotometry (NanoDrop, Thermo Scientific). A volume of $10 \mu \mathrm{L}$ containing $30 \mathrm{ng}$ of the RNA obtained was used for retro transcription following the procedure recommended in the Maxima $\mathrm{H}$ Minus First Strand cDNA Synthesis kit (Thermoscientific, $0.25 \mu \mathrm{L}$ of random hexamer primer, $1 \mu \mathrm{L}$ of $10 \mathrm{mM}$ dNTP mix, $3.75 \mu \mathrm{L}$ of nuclease-free $\mathrm{H}_{2} \mathrm{O}, 4 \mu \mathrm{L} 5 \times$ RT Buffer and $1 \mu \mathrm{L}$ Maxima H Minus Enzyme Mix). Controls were performed in the absence of the retro transcriptase enzyme (RT-, reverse transcriptase negative control).

\section{Quantitative polymerase chain reaction ( $q P C R$ )}

All the primers used generated amplification products of $200-\mathrm{bp}$ (Table 1). The efficiencies of all the primers used were around 100\% (Amdop1, 101.9\%; Amdop2, 104\%; Amdop3, 111.5\%; Amoa1, 95.7\%; Am5-ht1a, 107.5\%; Rps8, 111\%; Rp49, 101.5\%; 
Table 1. Primer sequences used to quantify RNA expression of genes of interest and reference genes by RT-qPCR

\begin{tabular}{|c|c|c|c|}
\hline Type of gene & Primer target & Primer sequence & Amplicon length (bp) \\
\hline \multirow[t]{9}{*}{ Genes of interest } & Amdop1 & $\begin{array}{l}\text { 5'-GAGTTATCCGAAGAATGTT (forward) } \\
\text { 5'-CGTTGAAGTTGATTATGAC (reverse) }\end{array}$ & 148 \\
\hline & Amdop2 & 5'-GGATCAACAGCGGAATGAAT (forward) & 151 \\
\hline & & 5'-GCGAATCTTTGACTCGGTTT (reverse) & \\
\hline & Amdop3 & 5'-CGTTGCAAACTGTCACCAAT (forward) & 155 \\
\hline & & 5'-GACGTCCATTGCGATGTAAA (reverse) & \\
\hline & Amoct $\alpha R 1$ & 5'-GAACGCCATCCAAGTGTTCT (forward) & 124 \\
\hline & & $5^{\prime}$-GTGCTTCCAACCCTGTTGAT (reverse) & \\
\hline & Am5-HT1a & 5'-GCCTCGATATTGCATCTGGT (forward) & 168 \\
\hline & & 5'-AGGATCCTTCCATCCGAGTT (forward) & \\
\hline \multirow[t]{6}{*}{ Reference genes } & Rps8 & 5'-ACGAGGTGCGAAACTGACTGA (forward) & 176 \\
\hline & & 5'-GCACTGTCCAGGTCTACTCGA (reverse) & \\
\hline & Rp49 & 5'-AAAGAGAAACTGGCGTAAACC (forward) & 126 \\
\hline & & 5'-CAGTTGGCAACATATGACGAG(reverse) & \\
\hline & Ef1a & 5'-AAGAGCATCAAGAGCGGAGA (forward) & 149 \\
\hline & & 5'-CGTACCTTAATGACGCCCACA (reverse) & \\
\hline
\end{tabular}

The length of the amplicons resulting from PCR is given.

$E f 1 \alpha, 103.6 \%)$. Expression was quantified using a SYBR Green realtime PCR method. Real-time PCR was carried out in Hard-Shell 96-Well PCR Plates (Bio-Rad) cover with Microseal "B" PCR plate sealing Film (Bio-Rad). The PCR reactions were performed using the SsAdvanced Universal SYBR Green Supermix (Bio-Rad) in a final volume of $20 \mu \mathrm{L}$ containing $10 \mu \mathrm{L}$ of $2 \times$ SsAdvanced Universal SYBR Green Supermix, $2 \mu \mathrm{L}$ of cDNA template (1:3 dilution from the reverse transcription reaction), $2.5 \mu \mathrm{L}$ of $10 \mu \mathrm{mol}$ of each primer (Table 1 ) and $5.5 \mu \mathrm{L}$ of ultrapure water. The reaction conditions were as follows: $95^{\circ} \mathrm{C}$ for $30 \mathrm{sec}$ followed by 40 cycles of $94^{\circ} \mathrm{C}$ for $5 \mathrm{sec}, 55^{\circ} \mathrm{C}$ for $30 \mathrm{sec}$ and plate read. and a final step at $95^{\circ} \mathrm{C}$ for $10 \mathrm{sec}$ followed by a melt curve from $55^{\circ} \mathrm{C}$ to $95^{\circ} \mathrm{C}$ with $0.5^{\circ} \mathrm{C}$ per sec. The reaction was performed in a CFX Connect Real-Time PCR Detection System and analyzed with the software Bio-Rad CFX Manager.

Each sample was run in triplicates. If the triplicates showed too much variability ( $\mathrm{SD}>0.3$ ), the furthest triplicate was discarded. If the two remaining triplicates still showed too much variability $(\mathrm{SD}>0.3)$ the sample was discarded.

The samples were subjected to a relative quantification and normalization. First for each sample and for each reference gene per brain region, the relative quantity $\left(Q_{r}\right)$ was computed using the difference between the mean Ct value of each sample and the highest mean Ct value $(\Delta \mathrm{Ct})$, using the following formula: $Q_{\mathrm{r}}=(1+E)^{\Delta \mathrm{Ct}}$ (with $E=$ efficiency of the reaction). Then a normalization factor for each sample was obtained computing the geometric mean of the relative quantities obtained for the reference genes in the corresponding samples $(\Delta \Delta \mathrm{Ct})$.

\section{Data analysis}

Latencies, velocities, and crossing events of behavioral experiments were extracted automatically by video analysis of the conditionings and memory tests. Learning curves were analyzed by performing two-way repeated measure analyses of variance (ANOVA) followed when necessary by post-hoc analysis using Dunnett's multiple comparisons test. If the sphericity criterion was not met for the repeated-measurement ANOVA, the GeisserGreenhouse's correction was applied, thus resulting in corrected degrees of freedom for some Fischer statistics. Memory tests were analyzed by performing Kruskal-Wallis tests (or Mann-Whitney tests) on the difference between the latencies to cross toward blue and green-illuminated compartments $\left(\Delta_{\text {latency }}=\right.$ latency blue latencygreen) followed when necessary by post-hoc analysis using Dunn's multiple comparisons test. Additionally, we assessed the presence of memory for each group by comparing the $\Delta_{\text {latency }}$ to a theoretical value of zero (indicating equal latencies to cross toward conditioned and unconditioned stimuli, hence the absence of memory) using Wilcoxon signed-rank test. Statistical differences between the gene expression of the paired and the unpaired groups were assessed for a given gene and brain region using a Student $t$-test after transformation of the data to improve normality and homoscedasticity (or Welch t-test in case of heteroscedasticity). No cross-comparisons between brain regions or genes were performed. Statistical analyses were performed using GraphPad Prism 8 software.

\section{Acknowledgments}

We thank two anonymous reviewers for useful remarks and criticisms on a previous version of our manuscript. M.E.V. thanks the Fyssen Foundation for post-doctoral support. H.G. thanks the University Paul Sabatier for doctoral support. M.G. thanks the Institut Universitaire de France, the CNRS, and the University Paul Sabatier for their support.

\section{References}

Agarwal M, Giannoni Guzmán M, Morales-Matos C, Del Valle Díaz RA, Abramson CI, Giray T. 2011. Dopamine and octopamine influence avoidance learning of honey bees in a place preference assay. PLoS One 6: e25371. doi:10.1371/journal.pone.0025371

Aso Y, Herb A, Ogueta M, Siwanowicz I, Templier T, Friedrich AB, Ito K, Scholz H, Tanimoto H. 2012. Three Dopamine pathways induce aversive odor memories with different stability. PLoS Genet 8: e1002768. doi:10 .1371/journal.pgen.1002768

Avalos A, Pérez E, Vallejo L, Pérez ME, Abramson CI, Giray T. 2017. Social signals and aversive learning in honey bee drones and workers. Biol Open 6: 41-49. doi:10.1242/bio.021543

Beggs KT, Tyndall JDA, Mercer AR. 2011. Honey bee dopamine and octopamine receptors linked to intracellular calcium signaling have a close phylogenetic and pharmacological relationship. PLoS One 6: e26809. doi:10.1371/journal.pone.0026809

Carcaud J, Roussel E, Giurfa M, Sandoz J-C. 2009. Odour aversion after olfactory conditioning of the sting extension reflex in honeybees. J Exp Biol 212: 620-626. doi:10.1242/jeb.026641

Claridge-Chang A, Roorda RD, Vrontou E, Sjulson L, Li H, Hirsh J, Miesenböck G. 2009. Writing memories with light-addressable reinforcement circuitry. Cell 139: 405-415. doi:10.1016/j.cell.2009.08 .034

Dacks AM, Riffell JA, Martin JP, Gage SL, Nighorn AJ. 2012. Olfactory modulation by dopamine in the context of aversive learning. $J$ Neurophysiol 108: 539-550. doi:10.1152/jn.00159.2012

Das G, Lin S, Waddell S. 2016. Remembering components of food in Drosophila. Front Integr Neurosci 10: 4. doi:10.3389/fnint.2016.00004

Dinges CW, Varnon CA, Cota LD, Slykerman S, Abramson CI. 2017. Studies of learned helplessness in honey bees (Apis mellifera ligustica). J Exp Psychol Anim Learn Cogn 43: 147-158. doi:10.1037/xan0000133

Erber J, Kloppenburg P. 1995. The modulatory effects of serotonin and octopamine in the visual system of the honey bee (Apis mellifera $\mathrm{L}$.) I. Behavioral analysis of the motion-sensitive antennal reflex. J Comp Physiol A 176: 119-129. doi:10.1007/BF00197757 
Farooqui T, Robinson K, Vaessin H, Smith BH. 2003. Modulation of early olfactory processing by an octopaminergic reinforcement pathway in the honeybee. J Neurosci 23: 5370-5380. doi:10.1523/JNEUROSCI .23-12-05370.2003

Farooqui T, Vaessin H, Smith BH. 2004. Octopamine receptors in the honeybee (Apis mellifera) brain and their disruption by RNA-mediated interference. J Insect Physiol 50: 701-713. doi:10.1016/j.jinsphys.2004 .04 .014

Giurfa M. 2006. Associative learning: the instructive function of biogenic amines. Curr Biol 16: R892-R895. doi:10.1016/j.cub.2006.09.021

Giurfa M. 2007. Behavioral and neural analysis of associative learning in the honeybee: a taste from the magic well. J Comp Physiol A 193: 801-824. doi:10.1007/s00359-007-0235-9

Giurfa M, Sandoz J-C. 2012. Invertebrate learning and memory: fifty years of olfactory conditioning of the proboscis extension response in honeybees. Learn Mem 19: 54-66. doi:10.1101/lm.024711.111

Giurfa M, Fabre E, Flaven-Pouchon J, Groll H, Oberwallner B, Vergoz V, Roussel E, Sandoz JC. 2009. Olfactory conditioning of the sting extension reflex in honeybees: memory dependence on trial number, interstimulus interval, intertrial interval, and protein synthesis. Learn Mem 16: 761-765. doi:10.1101/lm.1603009

Gold PE. 1986. The use of avoidance training in studies of modulation of memory storage. Behav Neural Biol 46: 87-98. doi:10.1016/S0163-1047 (86) $90927-1$

Gonzalez MC, Kramar CP, Tomaiuolo M, Katche C, Weisstaub N, Cammarota M, Medina JH. 2014. Medial prefrontal cortex dopamine controls the persistent storage of aversive memories. Front Behav Neurosci 8: 408. doi:10.3389/fnbeh.2014.00408

Guiraud M, Hotier L, Giurfa M, de Brito Sanchez MG. 2018. Aversive gustatory learning and perception in honey bees. Sci Rep 8: 1343. doi:10 .1038/s41598-018-19715-1

Hammer M, Menzel R. 1998. Multiple sites of associative odor learning as revealed by local brain microinjections of octopamine in honeybees. Learn Mem 5: 146-156.

Heisenberg M. 2003. Mushroom body memoir: from maps to models. Nat Rev Neurosci 4: 266-275. doi:10.1038/nrn1074

Izquierdo LA, Barros DM, Ardenghi PG, Pereira P, Rodrigues C, Choi H, Medina JH, Izquierdo I. 2000. Different hippocampal molecular requirements for short- and long-term retrieval of one-trial avoidance learning. Behav Brain Res 111: 93-98. doi:10.1016/S0166-4328(00) 00137-6

Izquierdo I, Bevilaqua LRM, Rossato JI, Bonini JS, Medina JH, Cammarota M. 2006. Different molecular cascades in different sites of the brain control memory consolidation. Trends Neurosci 29: 496-505. doi:10.1016/j.tins .2006 .07 .005

Jarvik ME, Kopp R. 1967. An improved one-trial passive avoidance learning situation. Psychol Rep 21: 221-224. doi:10.2466/pr0.1967.21.1.221

Kaminsky O, Klenerova V, Stöhr J, Sida P, Hynie S. 2001. Differences in the behaviour of Sprague-Dawley and Lewis rats during repeated passive avoidance procedure: effect of amphetamine. Pharmacol Res 44: 117122. doi: $10.1006 /$ phrs. 2001.0848

Kirkerud NH, Wehmann H-N, Galizia CG, Gustav D. 2013. APIS-a novel approach for conditioning honey bees. Front Behav Neurosci 7: 29. doi:10 $.3389 /$ fnbeh.2013.00029

Kirkerud NH, Schlegel U, Giovanni Galizia C. 2017. Aversive learning of colored lights in walking honeybees. Front Behav Neurosci 11: 94. doi:10 .3389/fnbeh.2017.00094

Kloppenburg P, Erber J. 1995. The modulatory effects of serotonin and octopamine in the visual system of the honey bee (Apis mellifera L.) II. Electrophysiological analysis of motion-sensitive neurons in the lobula. J Comp Physiol A 176: 111-118. doi:10.1007/BF00197758

Krypotos A-M. 2015. Avoidance learning: a review of theoretical models and recent developments. Front Behav Neurosci 9: 189. doi:10.3389/fnbeh .2015 .00189

LeDoux JE, Moscarello J, Sears R, Campese V. 2017. The birth, death and resurrection of avoidance: a reconceptualization of a troubled paradigm. Mol Psychiatry 22: 24-36. doi:10.1038/mp.2016.166

Lourenço AP, Mackert A, dos Santos Cristino A, Simões ZLP. 2008. Validation of reference genes for gene expression studies in the honey bee, Apis mellifera, by quantitative real-time RT-PCR. Apidologie (Celle) 39: 372-385. doi:10.1051/apido:2008015

McGaugh LJ. 1966. Time-dependent processes in memory storage. Science 153: $1351-1358$. doi:10.1126/science.153.3742.1351

McQuillan HJ, Barron AB, Mercer AR. 2012. Age- and behaviour-related changes in the expression of biogenic amine receptor genes in the antennae of honey bees (Apis mellifera). J Comp Physiol A 198: 753-761. doi:10.1007/s00359-012-0745-y

Menzel R. 1985. Learning in honey bees in an ecological and behavioral context. In Experimental behavioral ecology and sociobiology (ed. Hölldobler B, Lindauer M), pp. 55-74. Sinauer Associates, Stuttgart, Germany.
Menzel R. 2012. The honeybee as a model for understanding the basis of cognition. Nat Rev Neurosci 13: 758-768. doi:10.1038/nrn3357

Menzel R. 2014. The insect mushroom body, an experience-dependent recoding device. J Physiol Paris 108: $84-95$. doi:10.1016/j.jphysparis .2014 .07 .004

Menzel R, Greggers U. 1985. Natural phototaxis and its relationship to colour vision in honeybees. J Comp Physiol A 157: 311-321. doi:10 1007/BF00618121

Menzel R, Müller U. 1996. Learning and memory in honeybees: from behavior to neural substrates. Annu Rev Neurosci 19: 379-404. doi:10 $.1146 /$ annurev.ne.19.030196.002115

Mizunami M, Unoki S, Mori Y, Hirashima D, Hatano A, Matsumoto Y. 2009 Roles of octopaminergic and dopaminergic neurons in appetitive and aversive memory recall in an insect. BMC Biol 7: 46. doi:10.1186/ 1741-7007-7-46

Moncada D, Viola H. 2007. Induction of long-term memory by exposure to novelty requires protein synthesis: evidence for a behavioral tagging. $J$ Neurosci 27: 7476-7481. doi:10.1523/JNEUROSCI.1083-07.2007

Mota T, Roussel E, Sandoz J-C, Giurfa M. 2011. Visual conditioning of the sting extension reflex in harnessed honeybees. J Exp Biol 214: 35773587. doi:10.1242/jeb.062026

Mustard JA, Blenau W, Hamilton IS, Ward VK, Ebert PR, Mercer AR. 2003. Analysis of two D1-like dopamine receptors from the honey bee Apis mellifera reveals agonist-independent activity. Brain Res Mol Brain Res 113: 67-77. doi:10.1016/S0169-328X(03)00091-3

Netto CA, Izquierdo I. 1985. On how passive is inhibitory avoidance. Behav Neural Biol 43: 327-330. doi:10.1016/S0163-1047(85)91697-8

Perry CJ, Barron AB. 2013. Neural mechanisms of reward in insects. Annu Rev Entomol 58: 543-562. doi:10.1146/annurev-ento-120811-153631

Pfeiffer K, Homberg U. 2014. Organization and functional roles of the central complex in the insect brain. Annu Rev Entomol 59: 165-184. doi:10.1146/annurev-ento-011613-162031

Putz G, Heisenberg M. 2002. Memories in Drosophila heat-box learning. Learn Mem 9: 349-359. doi:10.1101/lm.50402

Reisenman CE, Giurfa M. 2008. Chromatic and achromatic stimulus discrimination of long wavelength (red) visual stimuli by the honeybee Apis mellifera. Arthropod Plant Interact 2: 137-146. doi:10.1007/ s11829-008-9041-8

Roozendaal B, McGaugh JL. 2011. Memory modulation. Behav Neurosci 125: 797-824. doi:10.1037/a0026187

Roussel E, Carcaud J, Sandoz J-C, Giurfa M. 2009. Reappraising social insect behavior through aversive responsiveness and learning. PLoS One 4: e4197. doi:10.1371/journal.pone.0004197

Roussel E, Sandoz J-C, Giurfa M. 2010. Searching for learning-dependent changes in the antennal lobe: simultaneous recording of neural activity and aversive olfactory learning in honeybees. Front Behav Neurosci 4: 155. doi:10.3389/fnbeh.2010.00155

Roussel E, Padie S, Giurfa M. 2012. Aversive learning overcomes appetitive innate responding in honeybees. Anim Cogn 15: 135-141. doi:10.1007/ s10071-011-0426-1

Scheiner R, Toteva A, Reim T, Søvik E, Barron AB. 2014. Differences in the phototaxis of pollen and nectar foraging honey bees are related to their octopamine brain titers. Front Physiol 5: 116. doi:10.3389/fphys.2014 .00116

Sinakevitch I, Mustard JA, Smith BH. 2011. Distribution of the octopamine receptor AmOA1 in the honey bee brain. PLoS One 6: e14536. doi:10 $.1371 /$ journal.pone. 0014536

Smith BH, Abramson CI, Tobin TR. 1991. Conditional withholding of proboscis extension in honeybees (Apis mellifera) during discriminative punishment. J Comp Psychol 105: 345-356. doi:10.1037/0735-7036.105 .4 .345

Tedjakumala SR, Giurfa M. 2013. Rules and mechanisms of punishment learning in honey bees: the aversive conditioning of the sting extension response. J Exp Biol 216: 2985-2997. doi:10.1242/jeb.086629

Tedjakumala SR, Aimable M, Giurfa M. 2014. Pharmacological modulation of aversive responsiveness in honey bees. Front Behav Neurosci 7: 221. doi:10.3389/fnbeh.2013.00221

Thamm M, Balfanz S, Scheiner R, Baumann A, Blenau W. 2010. Characterization of the 5-HT1A receptor of the honeybee (Apis mellifera) and involvement of serotonin in phototactic behavior. Cell Mol Life Sci 67: 2467-2479. doi:10.1007/s00018-010-0350-6

Tomaiuolo M, Katche C, Viola H, Medina JH. 2015. Evidence of maintenance tagging in the hippocampus for the persistence of long-lasting memory storage. Neural Plast 2015: 603672. doi:10.1155/ $2015 / 603672$

Unoki S, Matsumoto Y, Mizunami M. 2005. Participation of octopaminergic reward system and dopaminergic punishment system in insect olfactory learning revealed by pharmacological study. Eur J Neurosci 22: 14091416. doi:10.1111/j.1460-9568.2005.04318.x

Venable N, Kelly PH. 1990. Effects of NMDA receptor antagonists on passive avoidance learning and retrieval in rats and mice. Psychopharmacology (Berl) 100: 215-221. doi:10.1007/BF02244409 
Vergoz V, Roussel E, Sandoz J-C, Giurfa M. 2007. Aversive learning in honeybees revealed by the olfactory conditioning of the sting extension reflex. PLoS One 2: e288. doi:10.1371/journal.pone.0000288

Viola H, Furman M, Izquierdo LAI, Alonso M, Barros DM, de Souza MM, Izquierdo I, Medina JH. 2000. Phosphorylated cAMP response element-binding protein as a molecular marker of memory processing in rat hippocampus: effect of novelty. J Neurosci 20: RC112. doi:10.1523/ JNEUROSCI.20-23-j0002.2000.

Waddell S. 2010. Dopamine reveals neural circuit mechanisms of fly memory. Trends Neurosci 33: 457-464. doi:10.1016/j.tins.2010.07.001

Waddell S. 2013. Reinforcement signalling in Drosophila; dopamine does it all after all. Curr Opin Neurobiol 23: 324-329. doi:10.1016/j.conb.2013 .01 .005
Wustmann G, Heisenberg M. 1997. Behavioral manipulation of retrieval in a spatial memory task for Drosophila melanogaster. Learn Mem 4: 328336. doi:10.1101/lm.4.4.328

Wustmann G, Rein K, Wolf R, Heisenberg M. 1996. A new paradigm for operant conditioning of Drosophila melanogaster. J Comp Physiol A 179: 429-436. doi:10.1007/BF00194996

Wynne LC, Solomon RL. 1955. Traumatic avoidance learning: acquisition and extinction in dogs deprived of normal peripheral autonomic function. Genet Psychol Monogr 52: 241-284.

Received June 12, 2019; accepted in revised form August 2, 2019. 


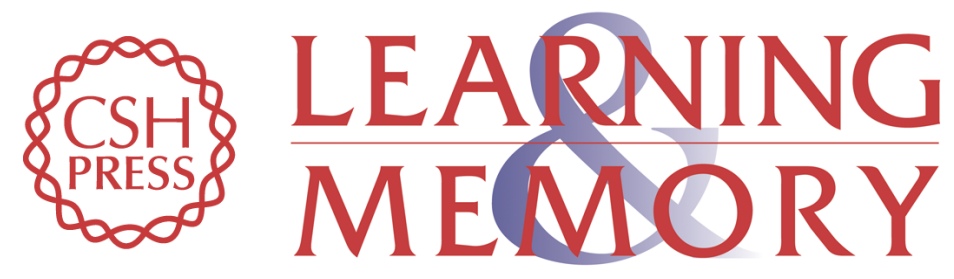

\section{Inhibitory learning of phototaxis by honeybees in a passive-avoidance task}

Paul Marchal, Maria Eugenia Villar, Haiyang Geng, et al.

Learn. Mem. 2019, 26:

Access the most recent version at doi:10.1101/Im.050120.119

References This article cites 66 articles, 13 of which can be accessed free at:

http://learnmem.cshlp.org/content/26/10/412.full.html\#ref-list-1

Creative This article is distributed exclusively by Cold Spring Harbor Laboratory Press for the

Commons first 12 months after the full-issue publication date (see

License

http://learnmem.cshlp.org/site/misc/terms.xhtml). After 12 months, it is available under a Creative Commons License (Attribution-NonCommercial 4.0 International), as described at http://creativecommons.org/licenses/by-nc/4.0/.

Email Alerting Receive free email alerts when new articles cite this article - sign up in the box at the Service top right corner of the article or click here. 